\title{
Trust Amongst Refugees in Resettlement Settings: a Systematic Scoping Review and Thematic Analysis of the Literature
}

\author{
Ryan Essex $^{1}$ (D) Erika Kalocsányiová ${ }^{1} \cdot$ Nataliya Rumyantseva $^{1,2} \cdot$ Jill Jameson $^{1}$
}

Accepted: 24 May 2021/Published online: 23 June 2021

(C) The Author(s) 2021

\begin{abstract}
Trust is of particular relevance to refugee populations, given the adverse, often protracted and liminal nature of the refugee journey. What trust means, how it shapes and is shaped by this journey, is crucially important for this population group and it can vary substantially. The extent, range and nature of research activity in this area are limited; this article therefore reports on a systematic scoping review that explored trust amongst refugees and asylum seekers in resettlement settings. Studies were included if they were primary research and explored trust amongst refugees and asylum seekers in a resettlement context and excluded if trust was not a major focus of the study (i.e. a number of studies were excluded that explored related concepts, such as social capital), if the study did not identify participants as refugees or asylum seekers or the study examined trust in a transitory setting. Following the application of inclusion and exclusion criteria, 24 studies remained, which were reviewed and analysed. Sixteen studies used qualitative methods, six used quantitative methods and one used mixed methods. Trust was presented as fundamentally relational, taking shape between and within refugees, asylum seekers and others. Trust was also presented as temporal and contextual, across refugee journeys, hardships experienced and resettlement. A major theme was the fundamental need in resettlement for a restoration of lost or damaged trust.
\end{abstract}

Keywords Trust - Trust and refugees $\cdot$ Refugee resettlement $\cdot$ Trust and migration $\cdot$ Scoping review $\cdot$ Systematic scoping review $\cdot$ Thematic analysis

Ryan Essex

r.w.essex@gre.ac.uk

1 Institute for Lifecourse Development, The University of Greenwich, Old Royal Naval College, Park Row, London SE10 9LS, UK

2 The Centre for Research on Employment and Work (CREW), The University of Greenwich, Old Royal Naval College, Park Row, London SE10 9LS, UK 


\section{Introduction}

Trust is indispensable for human life and society. Without trust, life would be chaotic and unpredictable (Luhmann, 2018); we would be 'suspicious of the friends we turn to for companionship, fearful of the specialists we must depend upon for vital services and information, and even distrustful of the food we must consume to nourish life' (Worchel, 1979). Trust helps us overcome this potential chaos, allowing us to act with some hope of certainty about others' behaviours and acting without fear of negative outcomes (Behnia, 2007).

Trust is of particular relevance to refugee populations, given the adverse, often protracted and liminal nature of the refugee journey. What trust means, how it shapes and is shaped by this journey, can vary substantially. When fleeing violence or persecution, it may not be clear who or what to trust: some may be betrayed and distrust may serve as a means to survive. Many will have suffered at the hands of the state: even by definition, 'refugees... fear rather than trust their home government' (Muecke, 1995). When fleeing, security, safety and certainty will remain threatened. Some may have little choice but to risk trusting those who would otherwise be untrustworthy. Many will take dangerous journeys to safety, while others will spend protracted periods in camps, where they continue to face unsafe and uncertain conditions.

If resettled, refugees then face a range of further challenges, navigating a new culture and language, new systems and institutions. Many will face ongoing difficulties within their own community and discrimination from society more generally and at the hands of government policy. How this trajectory plays out, however, will vary substantially between individuals, the countries from which they have fled and the country in which they hope to find safety.

Trust can be broadly described as an 'accepted vulnerability to another's possible but not expected ill will (or lack of good will)' (Baier, 1986). In other words, trust is one's willingness to be vulnerable to others, based on the expectation that one will not be harmed or exploited. While the ways in which trust is defined are subject to ongoing debate, all conceptualisations have a number of similarities. Trust is fundamentally relational and, as noted by Hall et al. (2001), almost all conceptualisations stress the 'optimistic acceptance of a vulnerable situation'. Related concepts are similarly important. Distrust is also commonly used alongside trust: however, distrust is not simply a lack of trust. We can, after all, not know whether to trust or distrust someone if we know too little about them. Distrust requires us to expect that someone will not fulfil their commitments. Furthermore, both trust and distrust relate to the idea of trustworthiness, that is, deciding who (or what) to trust is essentially, 'the challenge of working out who is trustworthy' (Hawley, 2012, p. 4).

In short, the importance of trust, more generally and in particular for refugee and asylum seeker populations, cannot be overstated. Given its critical role in resettlement, and the diversity of experience of refugees and asylum seekers, this article reviews the literature related to trust in refugee resettlement. The overarching aim of this systematic scoping review is therefore to synthesise and analyse the empirical literature on trust amongst refugees and asylum seekers in resettlement settings. More specifically, this review has two related aims: (1) to explore the nature and scope of the literature, identifying its strengths and shortcomings, and (2) to explore major themes related to trust in resettlement: what it means to refugees and asylum seekers and how it shapes and is shaped by displacement, transition and resettlement. 


\section{Methods}

\section{Design}

Given the above aims, a systematic scoping review was utilised to examine the extent, range and nature of research activity and to identify gaps in the existing literature on trust amongst refugees in resettlement (Arksey \& O'Malley, 2005). This involved the following steps: (1) identification of area of interest, (2) systematic literature search, (3) data extraction, (4) data synthesis and write-up. This review follows a data-based convergent synthesis design. That is, qualitative, quantitative and mixed-method studies were identified in a single search, integrated throughout analysis, synthesis and presentation (Noyes et al., 2019). Preferred Reporting Items for Systematic Reviews and Meta-Analyses (PRISMA) and enhancing transparency in reporting the synthesis of qualitative research (ENTREQ) reporting guidelines have been followed (Fig. 1) (Moher et al., 2009; Tong et al., 2012).

\section{Search Methods}

Nine reference databases were searched: Academic Search Premier, Medline, Psychology and Behavioral Sciences Collection, PsycInfo, CINAHL, PsycArticles, Scopus, Humanities International Complete and Web of Science. This review was part of a larger search that sought to explore trust and migration more generally. Preliminary search terms were developed to reflect a number of the core concepts: these were related to the population of interest (migrants, refugees and asylum seekers) and the concept of trust (trust, mistrust, distrust, trustworthiness). The final search terms used were (refugee or asylum seeker or displaced or migrant or immigrant) AND (trust or mistrust or distrust or trustworthiness). The final search was carried out in February 2020. Results were compiled; duplicates and articles from non-peer-reviewed sources were removed. After an initial review of the titles and abstracts of results, those that were obviously irrelevant articles were removed: 157 articles remained and were assessed against the following inclusion/exclusion criteria.

\section{Search Inclusion and Exclusion Criteria}

Against the below criteria, 22 articles were included from the above search. Reference lists in these articles were explored, and a further 2 articles were included. Therefore, 24 articles were included in this review. Papers were included if:

- They were primary research and explored trust amongst refugees and asylum seekers in a resettlement context. ${ }^{1}$

\footnotetext{
${ }^{1}$ For these purposes, we have used the generally accepted definition that refugees were resettled if they were residing in a state 'that has agreed to admit them and ultimately grant them permanent residence' (UNHCR, 2021).
} 


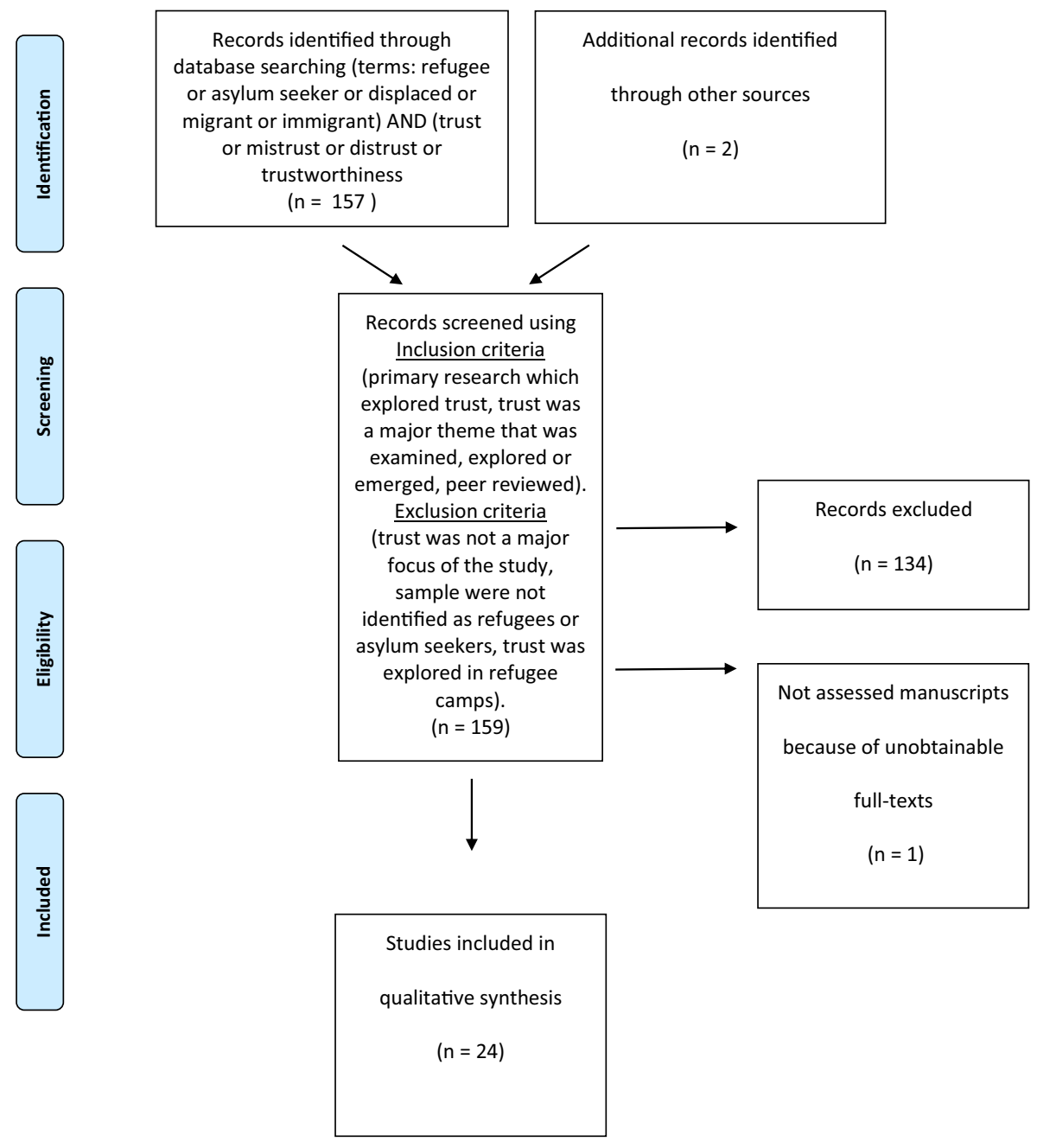

Fig. 1 PRISMA 2009 flow diagram

- Trust was a major theme that was examined, explored or emerged.

- The article was peer reviewed, available online and published in a credible scholarly source.

Papers were excluded if:

- Trust was not a major focus of the study. For example, a number of studies were excluded that explored related concepts, such as social capital, but said little about trust in itself.

- The study sample was not identified as refugees or asylum seekers. 
- They examined trust in refugee camps. While camps could be considered resettlement contexts, they are also often vastly different to other settings, presenting unique challenges related to safety, security and trust. ${ }^{2}$

\section{Data Extraction}

Data from the included studies was extracted by all authors and categorised according to the country in which the research took place, the study aims and objectives, the research methods/design and sample information, the measurements and analysis used and the main outcomes of the study. All authors examined the articles included for major themes that emerged.

\section{Data Summary and Synthesis}

Due to the heterogeneity that emerged in this dataset, across studies and even within similar study methodologies, a meta-analysis or combining of quantitative data for further analysis or a meta-synthesis for qualitative data was not possible. Instead, studies were combined to summarise descriptive study characteristics, followed by a thematic analysis (Mays et al., 2005). This approach identified major and recurring themes and was most appropriate to answer our research questions, given that the majority of studies included were qualitative and because of the depth of discussion related to trust found in these articles (Table 1).

\section{Results}

\section{Descriptive Results}

The majority of studies included in this review were carried out in the UK (7) (Goodall, 2010; Griffiths, 2012; Hynes, 2009, 2017; Majumder et al., 2015; O’Donnell et al., 2008; Rainbird, 2012) and Australia (5) (Correa-Velez et al., 2014; Lenette, 2015; Nickerson et al., 2019; Renzaho et al., 2013; Renzaho \& Polonsky, 2013). Two studies were carried out in Norway (Eide et al., 2018; Vårheim, 2014a, 2014b), Sweden (Björnberg, 2011; Linell \& Keselman, 2011) and Uganda (Lyytinen, 2017a), while studies also explored trust in Canada (Kyriakides et al., 2019), Ireland (Níraghallaigh, 2014), the Netherlands (Feldmann et al., 2007) and South Korea (Kim \& Kim, 2019). Two studies explored trust across a number of countries, including Syria, Lebanon, Jordan and Turkey (Melki \& Kozman, 2019) and Bosnia and the Netherlands (Mooren $\&$ Kleber, 2001). In regard to methodology, 17 studies used qualitative methods, six used quantitative methods and one used mixed methods. The combined sample size of

\footnotetext{
${ }^{2}$ We will discuss this further in our limitations below; however, we believe there is substantial scope to examine trust across the refugee journey and that trust in resettlement cannot be divorced from experiences pre and during migration. We also acknowledge that refugees and asylum seekers in camps and resettlement settings may face a number of similar challenges and that these will vary substantially depending on a range of contextual factors.
} 


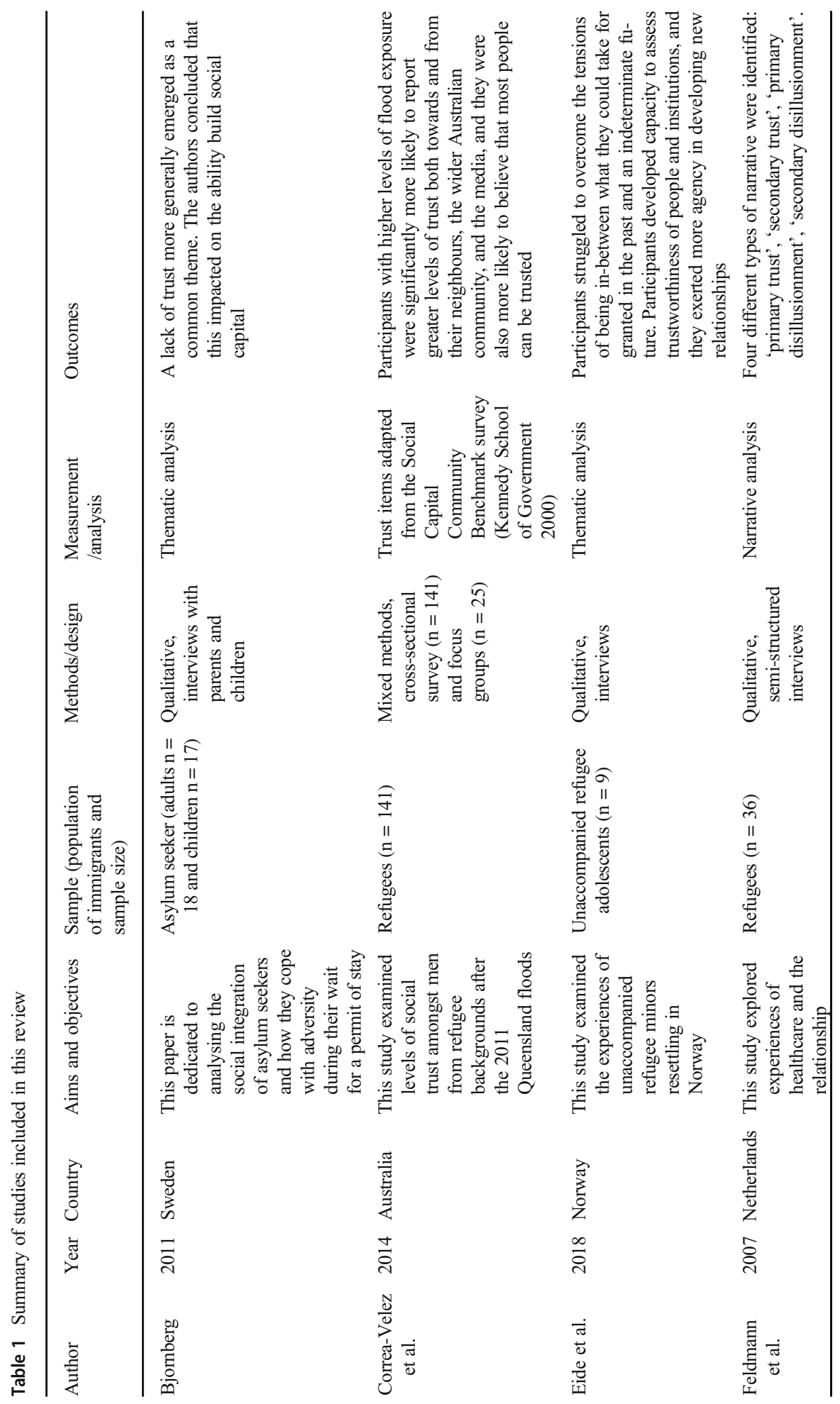




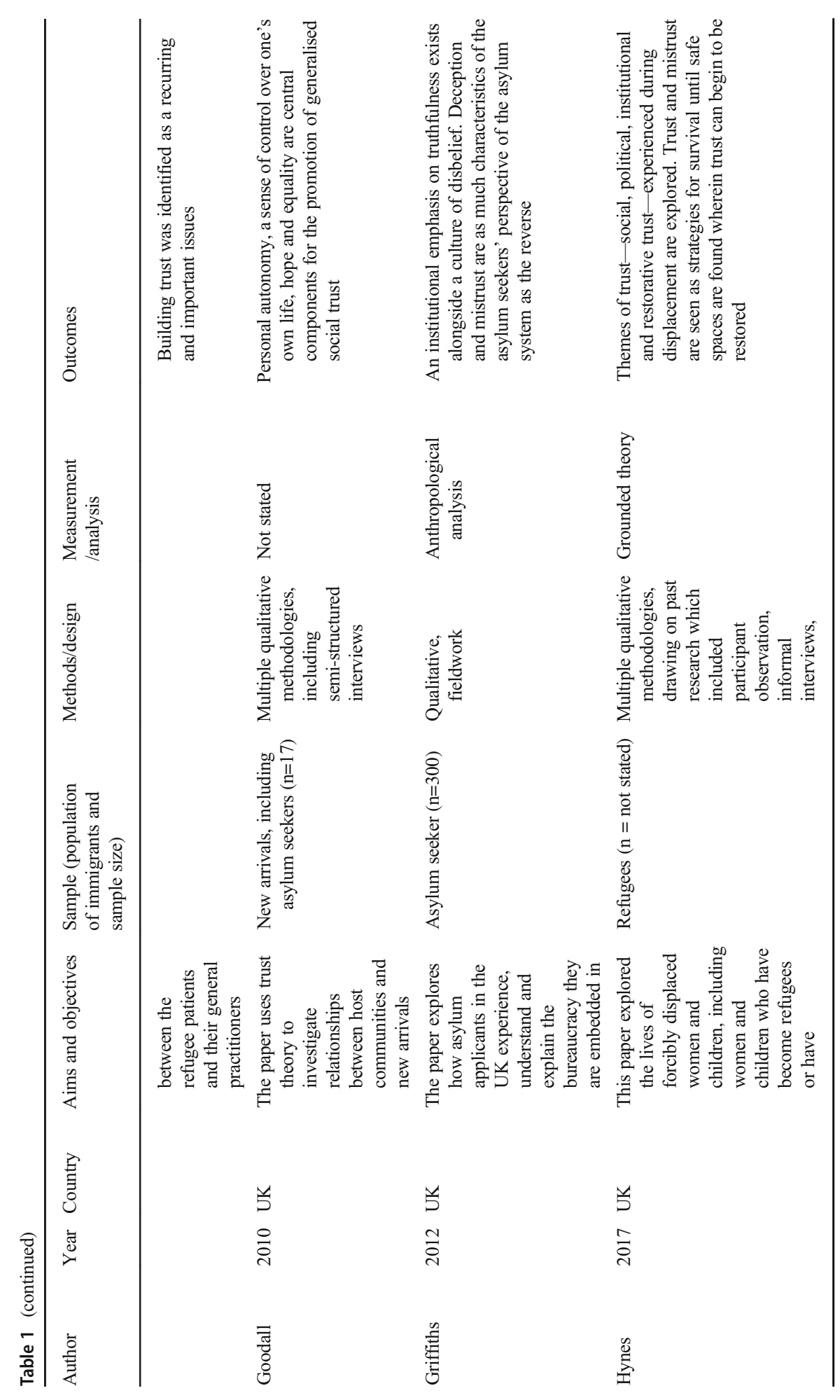




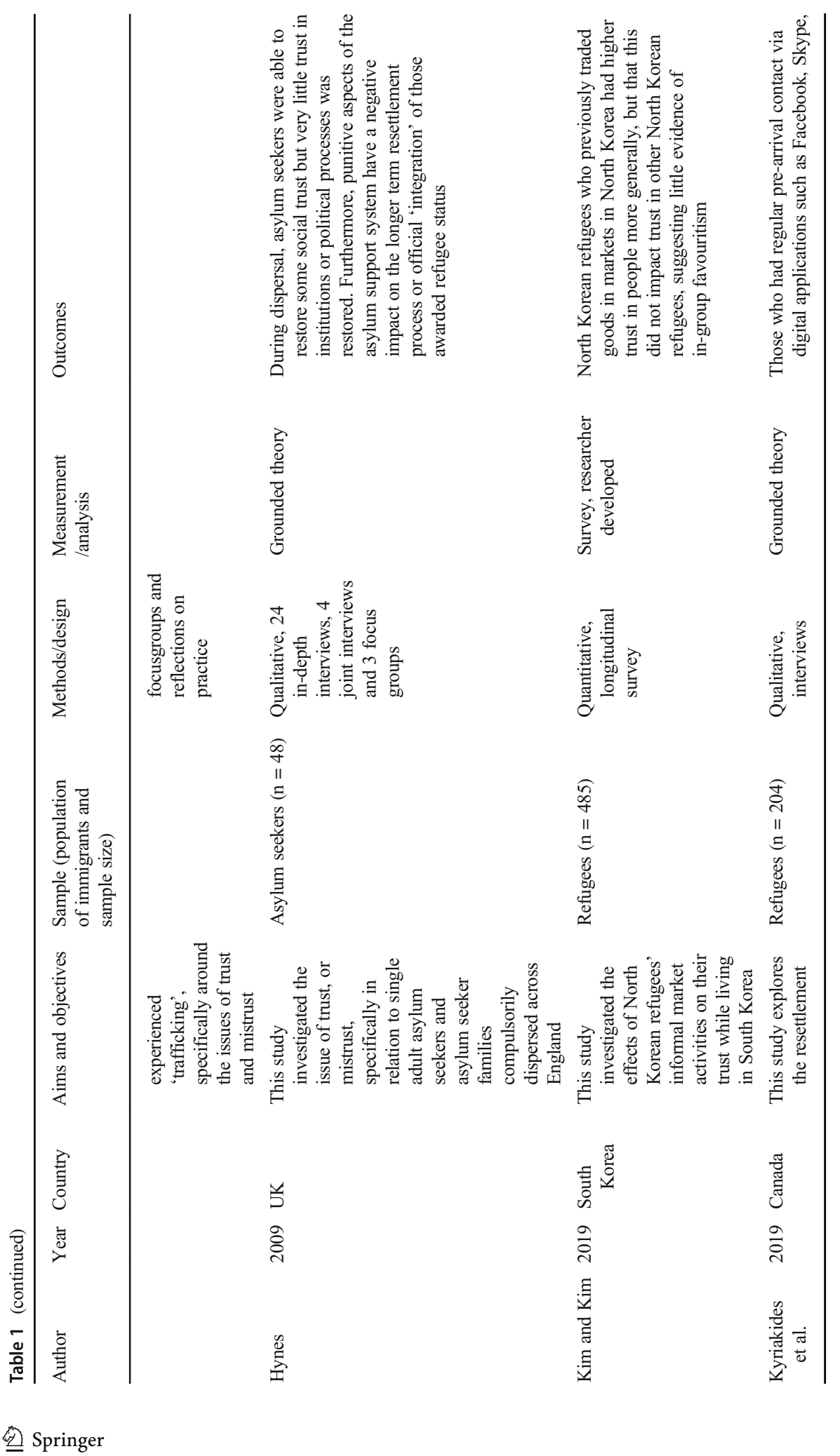




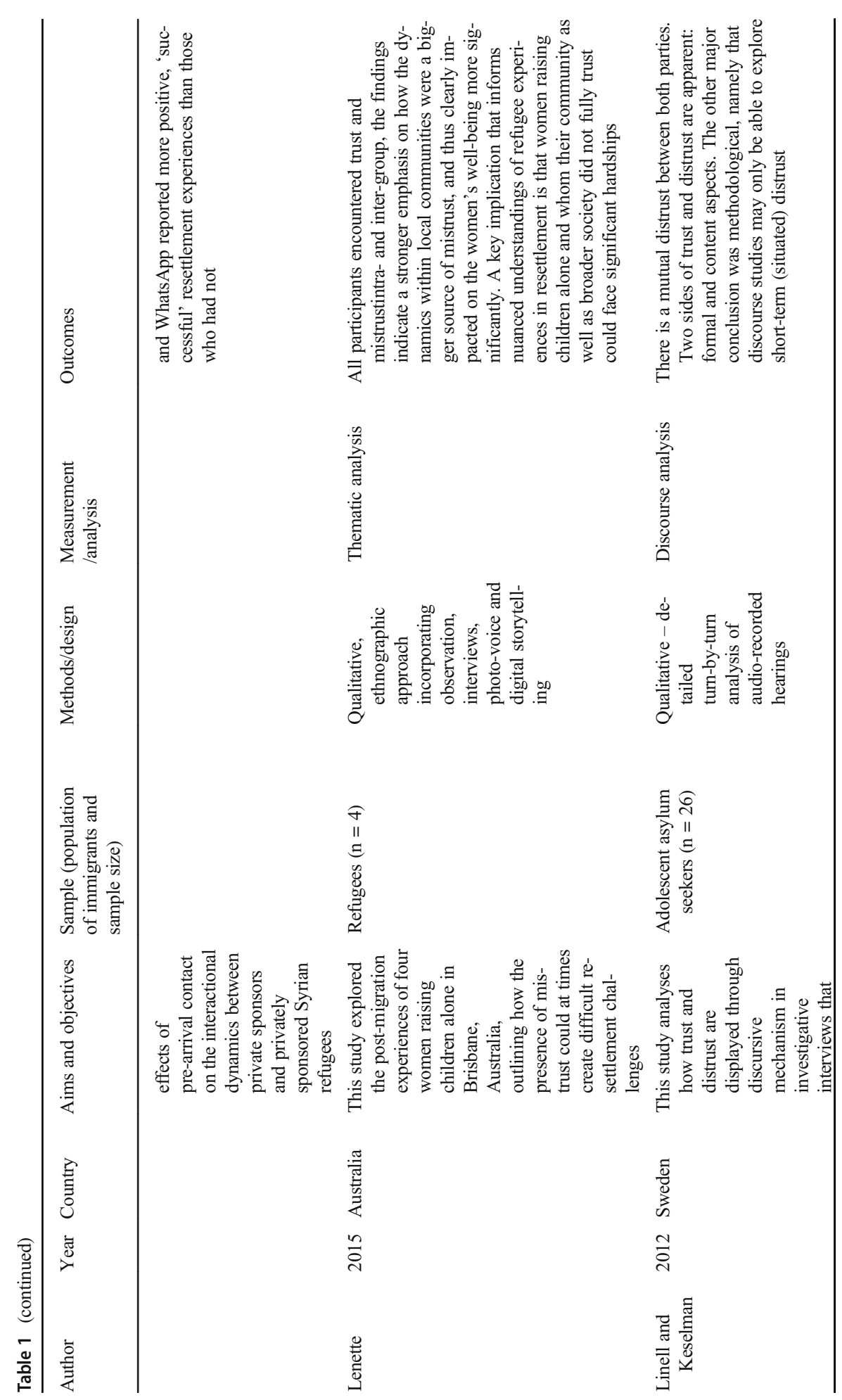




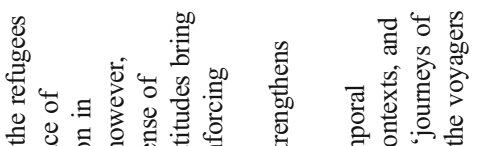

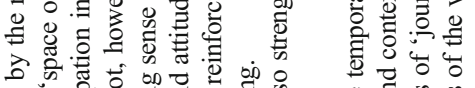

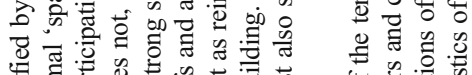

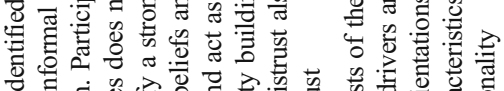

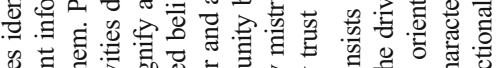

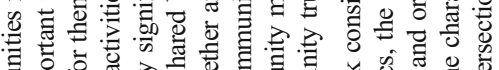

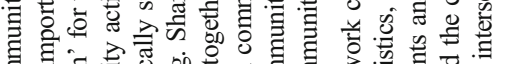

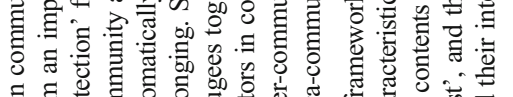

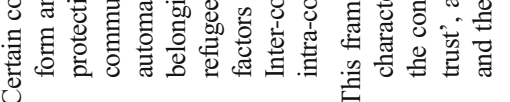

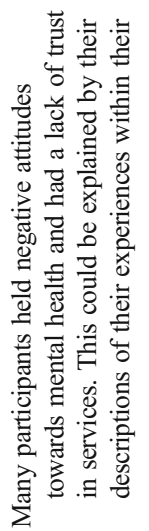

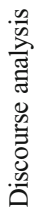

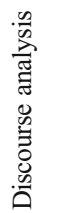

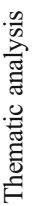
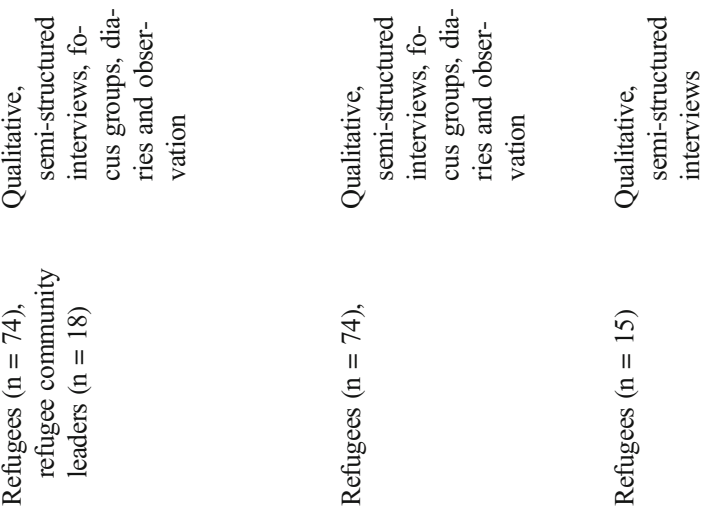

\begin{tabular}{|c|c|}
\hline & 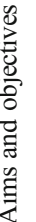 \\
\hline & 竧 \\
\hline 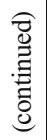 & छ \\
\hline$\frac{\bar{\varpi}}{\frac{\pi}{\sigma}}$ & 节 \\
\hline
\end{tabular}

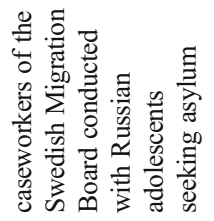

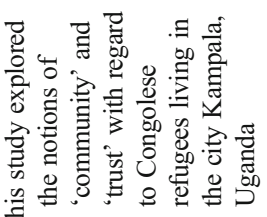

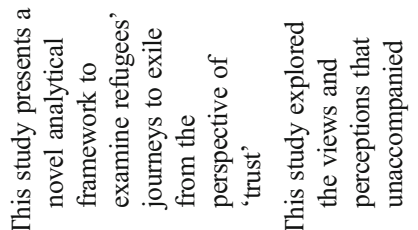

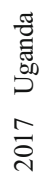

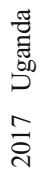

$\frac{\sqrt{2}}{11}$

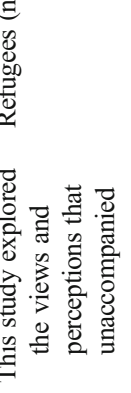

当

홍

ำ

离

竞

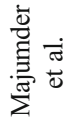




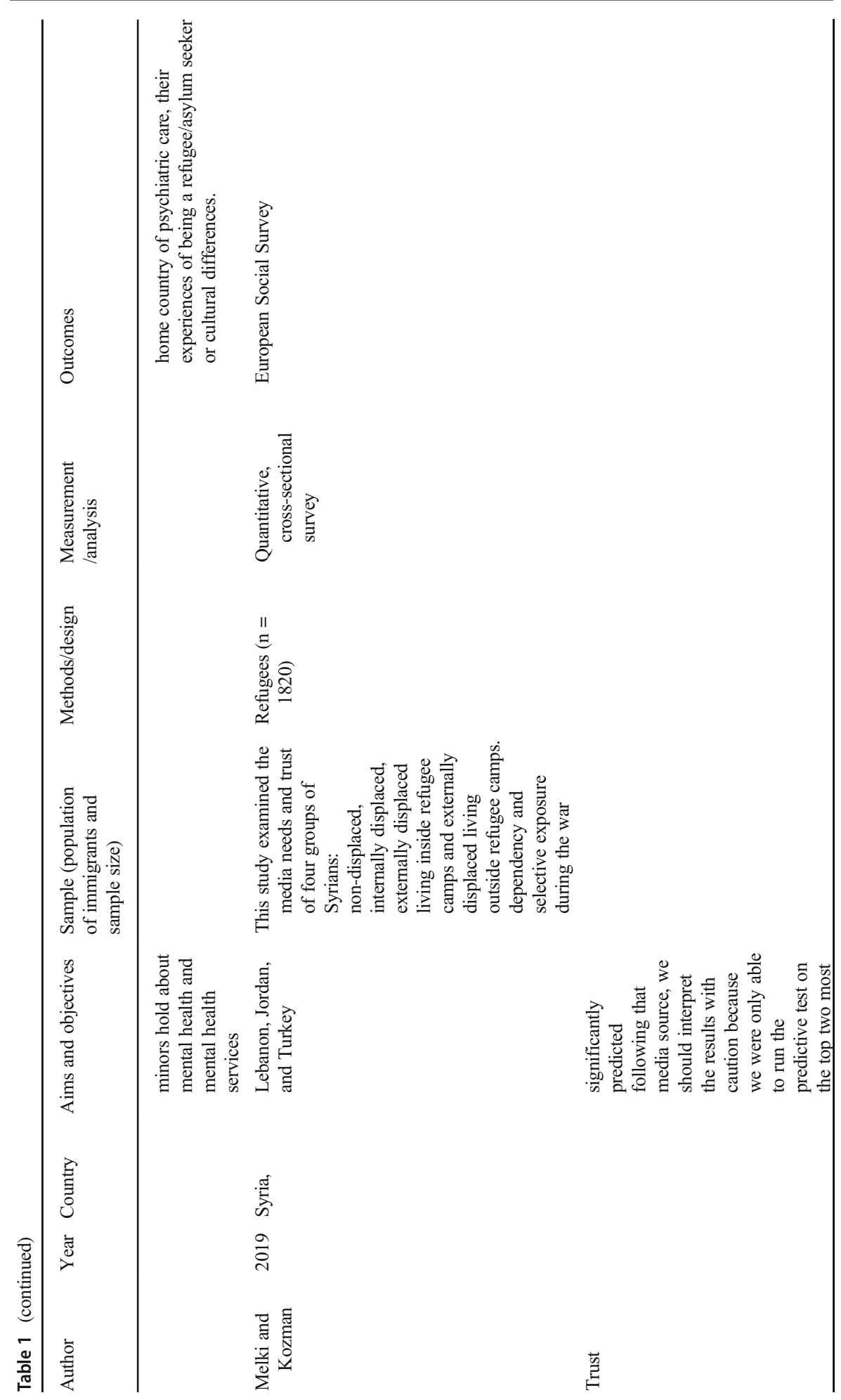




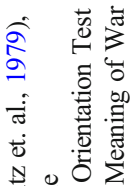

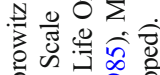

원.응응

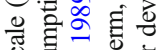

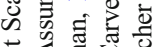

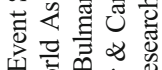

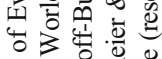

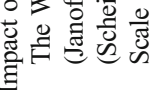

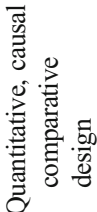

클

ถึ.

भ ष

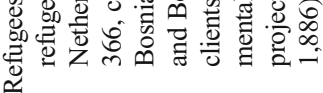

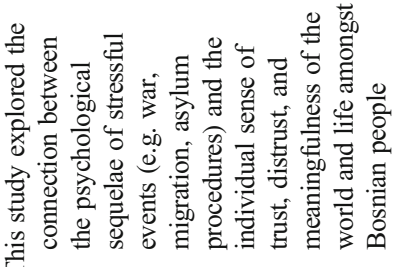

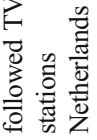

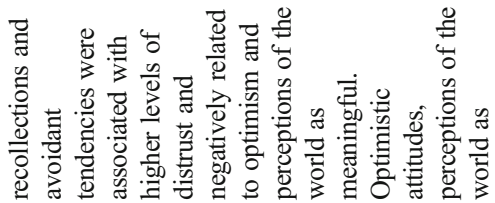

글

嗼

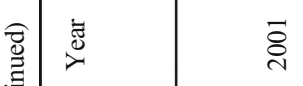

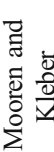




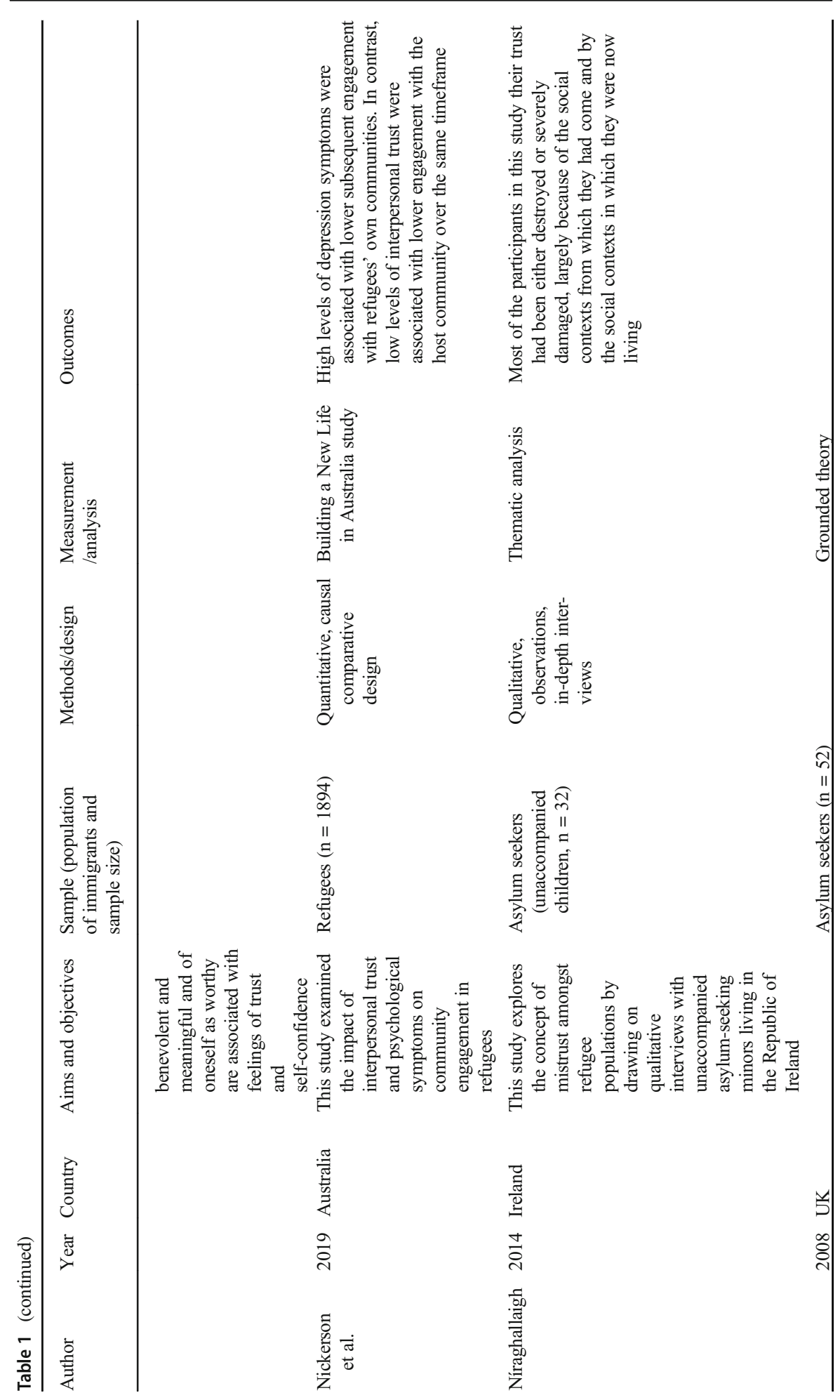




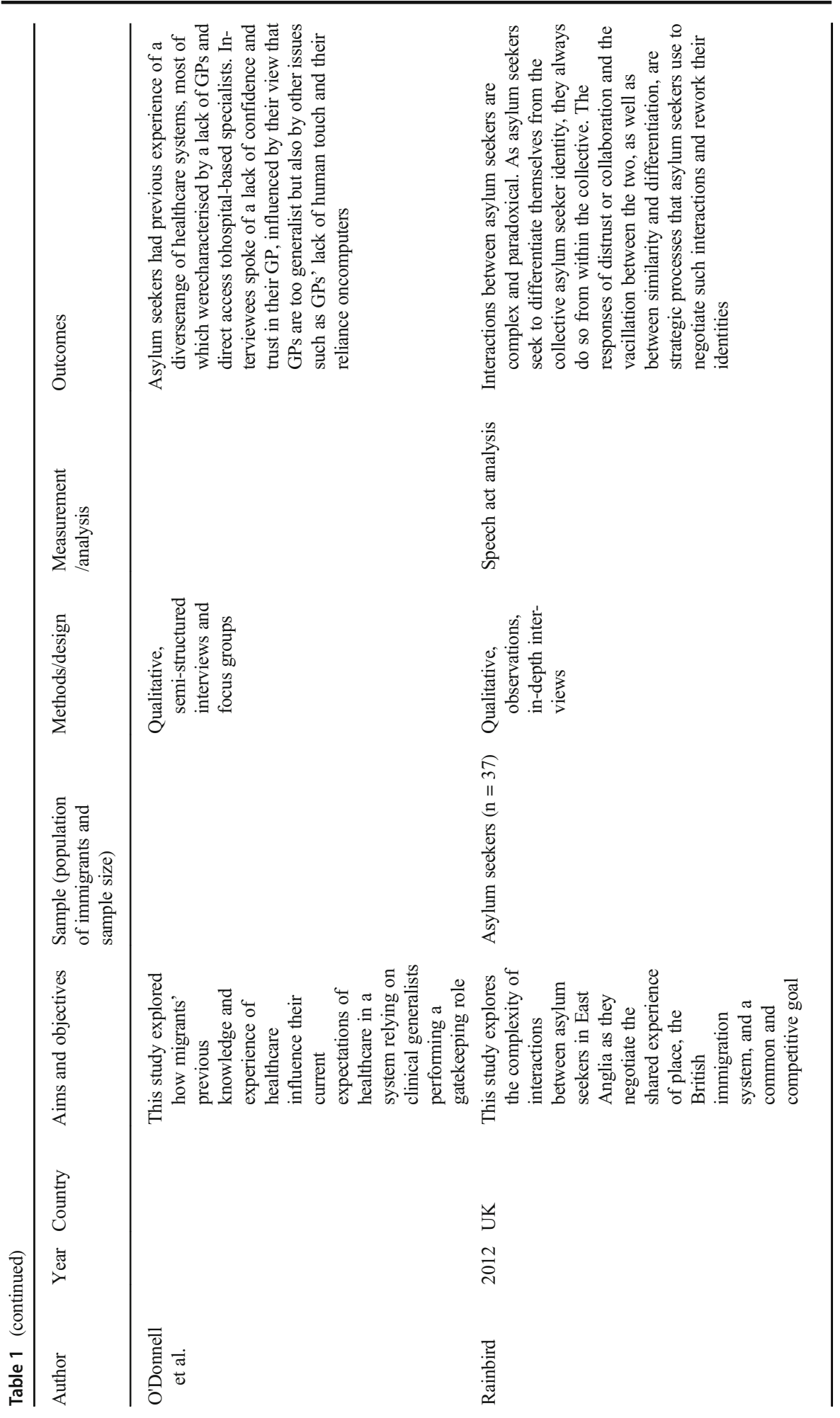




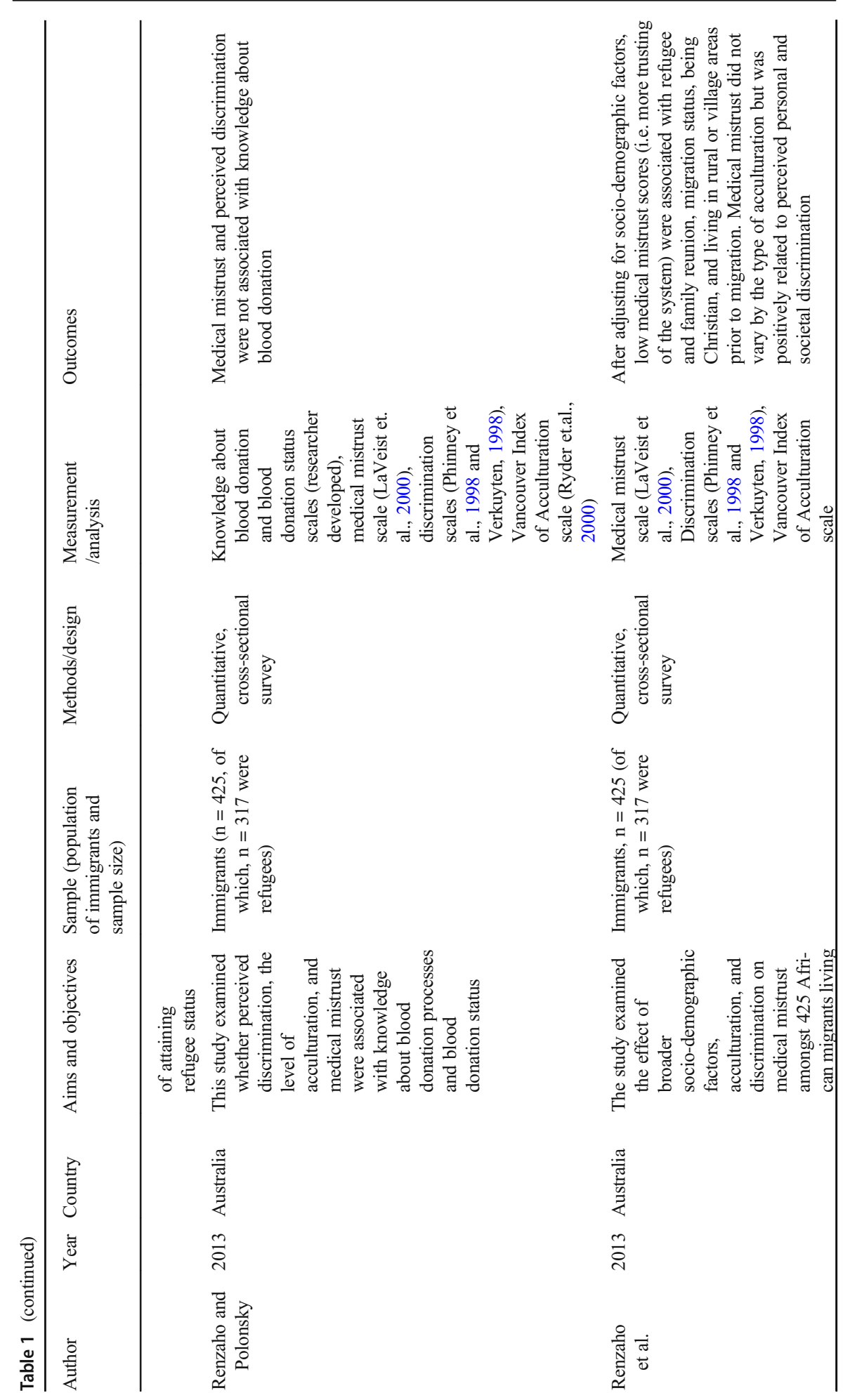




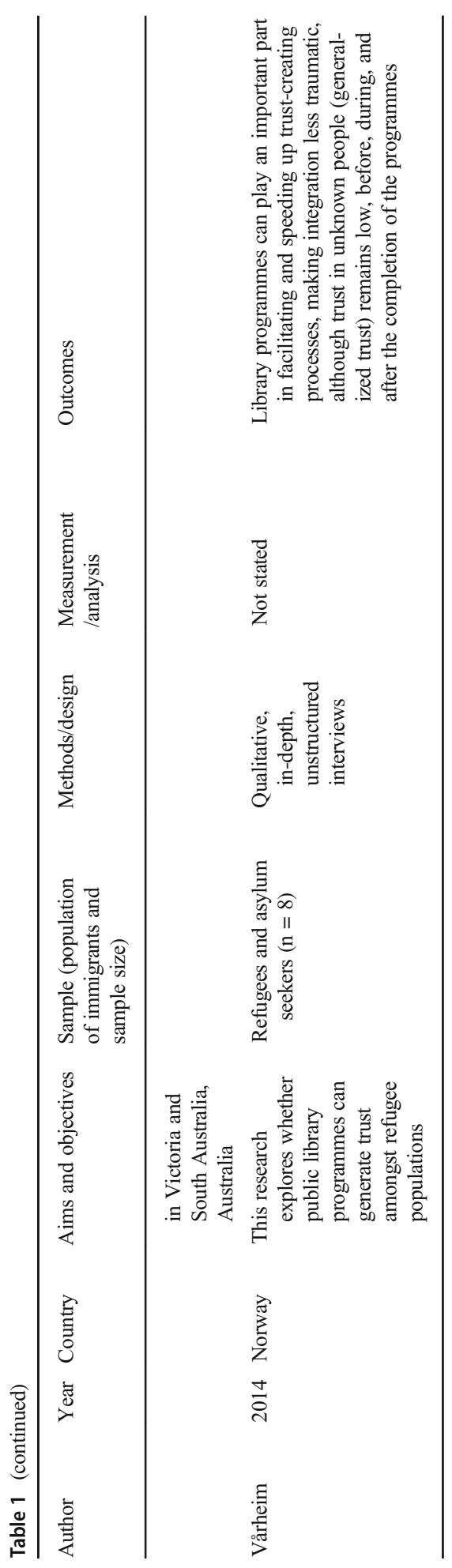


qualitative studies was 545. The combined sample size for the mixed methods study was 141. The combined sample size for the quantitative studies was 6519 .

\section{What is Trust?}

While the ways in which trust was conceptualised and the nature of the studies incuded in this review varied, trust emerged as a complex, multifaceted concept. Three themes emerged throughout the included articles related to the question of how refugees and asylum seekers conceptualised trust. First, trust was relational. Trust was explored between individuals and institutions and more broadly as a generally social phenomenon. Second, the relational nature of trust was not static; trust was reconceptualised and renegotiated throughout the migration journey and resettlement. Trust was also therefore dynamic. Third, trust was also shaped by the resettlement context. The studies below took place across a range of countries, in different settings and under a range of different circumstances. These factors (amongst others) were seen as important in conceptualising what trust meant for refugees and asylum seekers. Below, we will summarise the key findings related to the relational, dynamic and context-dependent nature of trust.

Trust was 'created, negotiated, sustained, confirmed or disconfirmed' (Linell \& Keselman, 2011, p. 156) amongst individuals and groups. Almost every study discussed the relational nature of trust and its contextual or situational qualities. Some drew distinctions between who or what was the object of trust. Hynes (2009), for example, suggests that looking at four forms of trust, social, political, institutional and restorative trust, could help begin to delineate the concept. This is an important point, as many of the studies below looked at trust amongst different individuals or institutions. Some focused on inter or intra-group trust (Lenette, 2015), others explored institutional trust more generally (Hynes, 2009), while others examined what could best be described as interpersonal trust, examining trust between General Practitioners (GPs) and refugees, for example (O'Donnell et al., 2008), or between refugees and their private sponsors in the country of resettlement (Kyriakides et al., 2019).

While in many cases it was helpful to isolate trust in certain interactions or between certain parties, in many studies, the distinction between who or what was trusted, and to what extent, was quite difficult to make. This was because, as noted above, trust was primarily relational and dynamic, that is, shaped by current and past relationships and shifting throughout the resettlement journey. O’Donnell et al. (2008), for example, explored trust amongst refugees and their GPs. This study suggested that while asylum seekers were generally pleased with the healthcare they received in the UK, their past experiences with their health and healthcare systems, and ongoing challenges in resettlement, shaped their expectations and trust in their GP. Similarly, Feldmann et al. (2007) investigated trust in healthcare services and GPs amongst Afghan refugees in the Netherlands and reached similar conclusions. However, they also showed that trust-building processes were not only based on the chain of personal experiences, but also on negative stories circulating in the community. Hynes (2017) discussed interpersonal trust between forcibly displaced women and children and a range of other parties involved in the long journeys of displacement (e.g. traffickers, partners, bystanders and soldiers) as well as institutional trust in relation to the state (in country of origin and in resettlement), linking it to the emergence of a broader social or generalised 
trust. Interestingly, Goodall (2010) questioned the role of direct personal experience in the emergence of generalised social trust; she considered fairness and equality, hope, autonomy and personal control as the central components of trust-building instead.

What trust meant between different individuals or groups varied substantially. Some results were unsurprising. Linell and Keselman (2011), for example, examined what could be labelled an interaction that was characterised by 'mutual mistrust', between immigration officials and unaccompanied children seeking asylum. The work of Griffiths (2012) also focused on the place of trust in the asylum system. Based on conversations with 300 asylum seekers in the UK, she found that 'deception, uncertainty and mistrust are as much characteristics of the asylum seekers' perspective of the immigration system as the reverse' (Griffiths, 2012, p. 8). However, trust as it played out between individuals and groups was often far more complex. Both Rainbird (2012) and Lenette (2015) challenged the assumption that refugees and asylum seekers would express greater trust for their in-group, that is, others from their country of origin. Rainbird (2012) explored how a group of asylum seekers in the UK negotiated their identity. Trust underpinned almost all interactions within this group. These were described as paradoxical, on the one hand, having to compete for resources and ultimately, asylum, while, on the other hand, also finding themselves in a situation that left them bound together, which at the same time promoted trust and friendship. Lenette (2015) also pained a complex picture. Exploring trust amongst a number of single refugee mothers, resettled in Australia, this study outlined the complex interplay of inter and intra-group trust, suggesting that the majority of mistrust existed within local communities (as opposed to the broader Australian community) because of the single mothers' marital status. Complicating this picture was the fact that while trusting relationships were established with the broader local community, these were often hampered by a number of community members' exclusionary attitudes. Kyriakides et al. (2019) presented cases where trust was built between incoming refugees and their private Canadian sponsors through pre-arrival communication via social media. Those who developed high levels of trust built their communication around pre-conflict roles and experiences (e.g. working in a particular profession and role in the family) of the refugees, with private sponsors sharing personal information in return and equalising the relationship. In cases where information was limited to procedural matters or no communication took place, trust did not emerge and was not recognised as missing by the refugees. Interestingly, when communication occurred in the context of trust, information was converted into a 'resettlement knowledge asset', providing valuable resources for the future. Finally, Lyytinen (2017a) utilised the idea of 'communities of trust' to explore trust amongst Congolese refugees living in Kampala, Uganda. Again, her findings are relatively complex, namely that while some communities formed important spaces of protection, community participation did not always signify a strong sense of belonging.

Trust was also dynamic. While some studies examined trust at a point in time or in one interaction (Linell \& Keselman, 2011), a number of studies conceptualised and explored trust as existing along a continuum between trust and mistrust and as shifting along a temporal trajectory (Hynes, 2017; Kyriakides et al., 2019): some did this across the refugee journey (Hynes, 2017), some focused on a digital 'third space' between departure and arrival locations (Kyriakides et al., 2019), while others did this for periods of time while in resettlement countries (Hynes, 2009; O'Donnell et al., 
2008). Lyytinen (2017b) makes a significant contribution in examining the temporal aspects of trust. She developed an analytical framework which combined the idea of the refugee 'journey' and trust. Drawing on fieldwork with Congolese refugees, living in Kampala, Uganda, she provides a framework to begin to consider the refugee journey, from fleeing danger or persecution, to finding safety and in resettlement. She proposes four elements that allow us to begin to better understand refugee 'journeys of trust': the temporal characteristics, the drivers and contexts, the contents and orientations of 'journeys of trust' and the individual characteristics of the voyagers and their intersectionality. Hynes (2017) similarly examines the idea of trust across the refugee journey amongst women and children, suggesting a continuum between trust and mistrust, while also importantly showing how trust and mistrust exist in parallel with the liminal nature of the refugee journey between displacement and emplacement. Kyriakides et al. (2019) developed these ideas further to discuss digital 'third spaces' of communication which bridge (or not) the space or departure with the destination of arrival. While not employing the idea of a 'journey', Feldmann et al. (2007) also showed how past experiences impacted current perceptions of trust, identifying how both positive and negative experiences, past and present, shaped refugees' trust towards their GP. Other studies examined the temporal nature of trust while refugees were in resettlement countries. Eide et al. (2018), for example, explored trust amongst unaccompanied refugee children resettled in Norway, suggesting that upon resettlement, while the children initially distrusted social workers and related institutions, trust developed over time. This was attributed to the extent to which participants began to exert greater agency over their lives and futures. Similarly, Níraghallaigh (2014) suggested an interactive relational nature of mistrust developed amongst unaccompanied minors in Ireland: that is, they were both mistrusting and mistrusted. A number of authors also considered the possibility of a shift away from initial trust to mistrust/ disillusionment, owing to unfair treatment by institutions, unemployment, lack of relevant language skills and social networks and experiences of discrimination (e.g. Feldmann et al., 2007; Rainbird, 2012; Vårheim, 2014a, 2014b).

The relational and dynamic nature of trust in refugee resettlement cannot be understood without taking the refugee journey into context. The studies analysed here were carried out in a range of different countries, which offered vastly different resettlement experiences. Those who participated in these studies also had vastly different experiences and expectations. Níraghallaigh (2014), for example, suggests that trust (and mistrust) was embedded in the social contexts from which asylum seekers have come and was exacerbated by the social contexts in which they are now living. O'Donnell et al. (2008) draw comparisons between, on the one hand, refugees' construction of trust in GP services in the UK on the basis of their experiences prearrival and the level of medical resources in the UK and, on the other, trust in GP services in their countries of displacement. Throughout all studies, trust is contrasted and complemented by a range of other phenomena that are also critical in resettlement, for example, integration and agency (Eide et al., 2018), ontological security (Hynes, 2009) and a range of social processes, such as social recognition, social identity and social capital (Björnberg, 2011). Almost all of the papers conceptualised mistrust as a survival mechanism, that is, throughout the refugee journey, many had learnt not to trust as a means to avoid being persecuted or exploited, and this often continued into resettlement (Hynes, 2017). 
There was also a recurring theme of restoration. That is, trust was something that has been damaged or destroyed, and that upon resettlement, it was something that needed to be re-established. How all of this occurs, however, was also dependent on the resettlement context. That is, policies in resettlement countries were seen to substantially impact the temporal trajectory of trust and to set the bounds regarding how trust is approached between individuals and groups. For example, Hynes (2009) suggests that the UK's policy of compulsory dispersal ${ }^{3}$ for asylum seekers impedes the restoration of trust at a very early stage of resettlement, which in turn has a range of negative implications for resettlement in the short and longer term.

This inevitably begins to overlap with the next major research question below. However, it is first worth commenting on how the quantitative studies included in this review conceptualised trust. The quantitative studies stand in contrast to the qualitative studies reported above. In conceptualising trust, many utilised scales which had single or a small number of questions used to measure trust. While giving little insight into the question of what trust is for refugees and asylum seekers, these studies shed more light on the second question below, namely in quantifying how trust shaped and was shaped by resettlement.

\section{The Impact of Trust on Resettlement and Resettlement on Trust}

All studies in this review saw trust as critically important in resettlement as a whole or at some point in the resettlement process. Most broadly, trust shaped a range of phenomena critical in resettlement and was in turn shaped by the resettlement process itself. The literature is again complex, and it is often difficult to pin down specific elements of the resettlement process that either damage or build trust. As is consistent with our discussion above, there is a degree of overlap below, namely many of the elements identified that impact on trust are also most fundamentally relational, dynamic and context dependent. A small number of studies below identified a number of premigratory experiences that impacted trust in resettlement. The majority of the studies, however, focused on trust in resettlement settings, along with the individual interpersonal sociocultural and institutional factors that shaped and were shaped by trust. Finally, there were at least four studies that explored trust as it related to very specific events in resettlement, trust and blood donation, trust as it related to the media and trust after a natural disaster. These studies will be discussed below.

A range of pre-migration experiences shaped trust. The studies suggest trauma and exposure to war were significant in shaping trust amongst refugees in resettlement and that this impacted participants' fundamental outlook on the world. Mooren and Kleber (2001), for example, found that in comparison to a group of Dutch students, Bosnian refugees were less optimistic, expressing less trust in others and in authorities. Furthermore, intrusive recollections were positively related to feelings of distrust and negatively associated with the perception of the world as meaningful. Past experiences also shaped trust in far more subtle ways. O'Donnell et al. (2008) and Feldmann et al. (2007) highlighted how participants' past experiences of healthcare shaped their expectations and perceptions of trust in relation to GPs. Kim and Kim (2019) found

\footnotetext{
${ }_{3}^{3}$ The broad aims of this policy were to redistribute asylum seekers receiving state support around the UK to prevent their concentration in the south-east of England.
} 
that North Korean refugees, resettled in South Korea, who previously traded goods in markets in North Korea, had higher trust in people more generally. Kyriakides et al. (2019) suggest that, amongst refugees being resettled in Canada, pre-arrival contact with sponsors facilitated trust between refugees and sponsors and facilitated the process of resettlement more generally.

Upon resettlement, a number of factors were identified as being critically important in shaping trust. Níraghallaigh (2014) explicitly set out to explore predictors of distrust amongst unaccompanied minors resettled in Ireland. As well as identifying past experiences that were important in shaping mistrust in resettlement, this study found further issues more closely related to resettlement itself, including being mistrusted by others. That is, a number of participants felt suspicion from the Irish public and institutions; unfamiliarity with people in Ireland; and concerns about truth telling, that is, for some of the participants, lying occurred because of a lack of trust: for example, they felt unable to tell their true reasons for leaving their countries of origin because of fears of repercussions. For others, however, mistrust was caused by the truth not being told, that is, if a participant was perceived to be lying or secretive about the truth, he or she was not trusted, and so, in return, he or she had difficulties trusting and becoming close to others. Björnberg (2011) similarly found that amongst asylum seekers resettled in Sweden, many felt themselves to be outsiders and had few opportunities for building social networks. Many kept a low profile and did not risk trusting people: what was called a 'wait and see' strategy. The relational nature of trust in resettlement was also quite complex, for example, high reliance on family increased the pressure to protect family members and, for children, ambiguous interdependency was often a burden, including having to suppress their needs of emotional support from mothers or friends. Lyytinen (2017a) found that amongst Congolese refugees living in Kampala, Uganda, shared beliefs and attitudes brought refugees together and acted as reinforcing factors in community building. However, this was not always the case, with participation in activities not guaranteeing a sense of belonging. This study also suggested that intercommunity mistrust also strengthens intra-community trust. Nickerson et al. (2019) quantified some of these findings, suggesting that amongst refugees resettled in Australia, lower levels of trust predicted lower levels of engagement with the 'host' community, but not refugees' own communities. There was also a relationship between trust and mental health symptoms, with those who had worse symptoms generally exhibiting less trust. The two studies that examined trust between refugee patients and their GPs revealed relatively specific factors that impacted trust. Feldmann et al. (2007), for example, emphasised the importance of the affective elements of GP appointments, including the perceived interest from the GP and their friendliness. O'Donnell et al. (2008) similarly suggest that continuity of care and perceptions about the GP listening and caring about the patient were important. The use of a computer in consultations was found to have a negative impact on trust, as did approaching the appointment in a patient-centred fashion, with many participants expecting the GP to take control of the consultation. Beyond these largely interpersonal factors, sociocultural factors were also found to impact trust. Lenette (2015) suggested that gender and culture both played a role in shaping trust and, for a number of refugee women who were parents, resettled in Australia, identifying the fact that while they relied heavily on local communities for support in the early stages of development, distrust was a particular issue within their immediate community of those who shared a similar background; many isolated 
women felt they were excluded or stigmatised within their local communities because of their marital status. Finally, Hynes (2017) introduces the concept of 'cultural and ideological somersaults' to highlight how some refugees asserted agency, turning traumatic experiences into valuable survival tools and reframing these experiences upon resettlement.

In addition to the above individual, interpersonal and sociocultural factors, a number of authors identified broader policy and institutional factors that shaped trust. Trust amongst unaccompanied minors resettled in Norway was influenced in part by their care institution requirements, rules and regulations (Eide et al., 2018). Occasionally, distrust in broader institutions was misattributed. Majumder et al. (2015), for example, found that amongst a number of unaccompanied refugee minors resettled in the UK, there was a general mistrust of healthcare services. Many saw health professionals as representatives of the state and were fearful of deportation. Rainbird (2012), who examined trust amongst a group of asylum seekers resettled in the UK, suggested that while the relationship between asylum seekers was complex, distrust was common, as they had to compete for immigration status and resources. This 'competition' could be seen as a direct result of the UK's asylum policy. Hynes (2009) suggests the UK's compulsory dispersal policy hindered trust and had more general implications on resettlement. In saying this, a number of institutions were seen as facilitating trust. Björnberg (2011), for example, also suggests that while trust could be negatively impacted if institutions applied rules that were opaque or inconsistent, schools, churches, voluntary organisations and healthcare institutions were generally trusted and played an important role in building trust and well-being. Vårheim, 2014a, 2014b) found that amongst refugees enrolled in library programmes, participants became more trusting of libraries as institutions and of library patrons and users. However, this did not generalise into social trust outside of the library setting. In saying this, however, institutional trust that refugees developed on arrival may erode over time, particularly if these institutions are 'unable or unwilling to support them for an extended period of time' (Lyytinen, 2017b). Vårheim, 2014a, 2014b) similarly found that:

... [the fact that] former students are less trusting towards strangers, compared with current students, is perhaps worrying in terms of the integration of immigrants in Norwegian society. The lowered trust could, however, be the result of the wearing off of the 'honeymoon effect' indicating that the trust patterns of newcomers are unstable, and that they need some time in the host country before core attitudes such as social trust are stabilized. (p. 66)

A number of other studies examined trust as it related to relatively specific elements of resettlement. Amongst a larger study of Syrian refugees, Melki and Kozman (2019) found that trust in media sources predicted whether participants followed that media source, while, perhaps unsurprisingly, and consistent with the broader literature in this area, this study perhaps has lessons for communication in resettlement more generally. In two papers, Renzaho et al. (2013) and Renzaho and Polonsky (2013) found that 'medical mistrust' was not associated with acculturation but was related to perceived discrimination. Mistrust was also not associated with knowledge about blood donation or those who had donated blood, while discrimination was. Finally, a study that is relatively unique amongst all those above examined how a natural disaster impacted trust. Correa-Velez et al. (2014) examined trust amongst refugees in Australia, after exposure to the 2011 Queensland floods. The results of this study suggest that 
participants with higher levels of flood exposure were significantly more likely to report greater levels of trust both towards and from their neighbours, the wider Australian community and the media, and they were also more likely to believe that most people could be trusted.

\section{Discussion}

Amongst studies that explored trust amongst refugees in resettlement contexts, trust was presented as fundamentally relational, occurring between and within refugees and asylum seekers and other individuals, groups and entities. Trust was also presented as having a temporal aspect, across the refugee journey as a whole and throughout resettlement. In examining the relational and temporal elements of trust, context is needed, as trust cannot be viewed in isolation of the broader hardships often faced throughout the journey and after arrival in resettlement countries. A major theme throughout the above articles was one of restoration, that is, amongst refugees and asylum seekers, trust had been lost or in some way damaged and that it was fundamental to re-establish this in resettlement. In addition to a range of past experiences, numerous factors were seen as important in the restoration of trust in resettlement. Generally, supportive individuals and institutions were seen as important foundations. However, a one-size-fits-all approach cannot be assumed. Individual actions of otherwise trustworthy individuals were revealed to erode trust, while potentially traumatic and uncontrollable circumstances, like the floods in Queensland, were revealed to build trust.

Collectively, the literature included in this review has several strengths and shortcomings. In relation to strengths, the literature presented above provides a detailed and nuanced picture of trust, a relatively complex concept. The literature sheds light on how trust is shaped throughout the refugee journey and in resettlement. Importantly, we can begin to draw conclusions about 'how' trust is built in resettlement settings. In saying this, there is substantial scope for future research to build on the shortcomings of this literature and issues that have been overlooked. First, there are few studies that explore trust in resettlement across the refugee journey or in resettlement itself over the longer term, that is, from the time that refugees arrive, well into resettlement. Expanding the scope of such research, however, particularly related to trust, will not be easy, and this review itself focused only on resettlement settings, largely for practical reasons. The concept of the refugee 'journey' itself has been long discussed (BenEzer \& Zetter, 2015; Lyytinen, 2017b) and, furthermore, given the vastly different circumstances facing refugees across the world today, it may be that any findings across the refugee journey are simply not generalisable. This is not a problem in itself and again perhaps speaks to the complex and dynamic nature of trust. In saying this, there are a number of further directions in which we see future research having a particular impact. Second, there is scope to explore the impact of pre-migration experiences on trust. For example, those surviving war may have significantly different experiences from those surviving human trafficking. Third, individual factors deserve greater attention. While a number of studies explored the experiences of unaccompanied minors, only one applied a gendered lens to explore the experiences of single refugee women. Further research should consider the merits of such an approach and the need to explore research with 
other vulnerable groups, such as the elderly, LGBTQI individuals or those with a disability. Fourth, there is substantial scope to examine how trust relates to other concepts critical in resettlement; hope, acculturation, isolation and integration are a few examples. Fifth, trust is context dependent (see Castree, 2005; Simandan, 2019; Withers, 2018). There is substantial scope to further explore factors that facilitate or erode trust. These factors could be dependent on individual differences, cultural and linguistic differences, pre-migration experiences and the post-migration structures to support resettlement, amongst other factors. Sixth, care and greater depth of insight is needed, particularly with quantitative research related to how trust is conceptualised. The qualitative literature stands in contrast, painting a nuanced and detailed picture of trust. Many of the quantitative studies included here appeared to take these subtleties for granted. Finally, there is a need for greater engagement with the literature on resettlement more generally.

Open Access This article is licensed under a Creative Commons Attribution 4.0 International License, which permits use, sharing, adaptation, distribution and reproduction in any medium or format, as long as you give appropriate credit to the original author(s) and the source, provide a link to the Creative Commons licence, and indicate if changes were made. The images or other third party material in this article are included in the article's Creative Commons licence, unless indicated otherwise in a credit line to the material. If material is not included in the article's Creative Commons licence and your intended use is not permitted by statutory regulation or exceeds the permitted use, you will need to obtain permission directly from the copyright holder. To view a copy of this licence, visit http://creativecommons.org/licenses/by/4.0/.

\section{References}

Arksey, H., \& O'Malley, L. (2005). Scoping studies: Towards a methodological framework. International Journal of Social Research Methodology, 8(1), 19-32.

Baier, A. (1986). Trust and antitrust. Ethics, 96(2), 231-260.

Behnia, B. (2007). Trust development: A discussion of three approaches and a proposed alternative. British Journal of Social Work, 38(7), 1425-1441.

BenEzer, G., \& Zetter, R. (2015). Searching for directions: Conceptual and methodological challenges in researching refugee journeys. Journal of Refugee Studies, 28(3), 297-318.

Björnberg, U. (2011). Social relationships and trust in asylum seeking families in Sweden. Sociological Research Online, 16(1), 100-108.

Castree, N. (2005). The epistemology of particulars: Human geography, case studies and 'context'. Geoforum, 36(5), 541-544.

Correa-Velez, I., McMichael, C., \& Conteh, A. (2014). Levels of social trust among men from refugee backgrounds after the 2011 Queensland floods. International Journal of Disaster Resilience in the Built Environment

Eide, K., Lidén, H., Haugland, B., Fladstad, T., \& Hauge, H. A. (2018). Trajectories of ambivalence and trust: Experiences of unaccompanied refugee minors resettling in Norway. European Journal of Social Work, $1-12$.

Feldmann, C. T., Bensing, J. M., De Ruijter, A., \& Boeije, H. R. (2007). Afghan refugees and their general practitioners in The Netherlands: To trust or not to trust? Sociology of Health \& Illness, 29(4), 515-535.

Goodall, C. (2010). The coming of the stranger: Asylum seekers, trust and hospitality in a British city. UNCR. New issues in refugee research. Research paper no. 195.

Griffiths, M. (2012). 'Vile liars and truth distorters'; Truth, trust and the asylum system. Anthropology Today, 28(5), 8-12.

Hall, M. A., Dugan, E., Zheng, B., \& Mishra, A. K. (2001). Trust in physicians and medical institutions: What is it, can it be measured, and does it matter? The Milbank Quarterly, 79(4), 613-639.

Hawley, K. (2012). Trust: A very short introduction. Oxford University Press. 
Horowitz, M., Wilner, N., \& Alvarez, W. (1979). Impact of event scale: A measure of subjective stress. Psychosomatic Medicine, 41(3), 209-218.

Hynes, P. (2009). Contemporary compulsory dispersal and the absence of space for the restoration of trust. Journal of Refugee Studies, 22(1), 97-121.

Hynes, P. (2017). Trust and mistrust in the lives of forcibly displaced women and children. Families, Relationships and Societies, 6(2), 219-237.

Janoff-Bulman, R. (1989). Assumptive worlds and the stress of traumatic events: Applications of the schema construct. Social Cognition, 7(2), 113-136.

Kim, B. Y., \& Kim, S. H. (2019). Market activities and trust of North Korean refugees. Asian Economic Policy Review, 14(2), 238-257.

Kyriakides, C., McLuhan, A., Anderson, K., Bajjali, L., \& Elgendy, N. (2019). (Mis) Trusted contact: Resettlement knowledge assets and the third space of refugee reception. Refuge, 35(2), 24-35.

LaVeist, T. A., Nickerson, K. J., \& Bowie, J. V. (2000). Attitudes about racism, medical mistrust, and satisfaction with care among African American and white cardiac patients. Medical Care Research and Review, 57(1_suppl), 146-161.

Lenette, C. (2015). Mistrust and refugee women who are lone parents in resettlement contexts. Qualitative Social Work, 14(1), 119-134.

Linell, P., \& Keselman, O. (2011). Trustworthiness at stake: Trust and distrust in investigative interviews with Russian adolescent asylum-seekers in Sweden. In I. Markova \& A. Gillespie (Eds.), Trust and Conflict (pp. 156-180). London.

Luhmann, N. (2018). Trust and power. John Wiley \& Sons.

Lyytinen, E. (2017a). Informal places of protection: Congolese refugees' 'communities of trust' in Kampala, Uganda. Journal of Ethnic \& Migration Studies, 43(6), 991-1008.

Lyytinen, E. (2017b). Refugees' 'journeys of trust': Creating an analytical framework to examine refugees' exilic journeys with a focus on trust. Journal of Refugee Studies, 30(4), 489-510.

Majumder, P., O'Reilly, M., Karim, K., \& Vostanis, P. (2015). 'This doctor, I not trust him, I'm not safe': The perceptions of mental health and services by unaccompanied refugee adolescents. International Journal of Social Psychiatry, 61(2), 129-136.

Mays, N., Pope, C., \& Popay, J. (2005). Systematically reviewing qualitative and quantitative evidence to inform management and policy-making in the health field. Journal of Health Services Research \& Policy, 10(1_suppl), 6-20.

Melki, J., \& Kozman, C. (2019). Media dependency, selective exposure and trust during war: Media sources and information needs of displaced and non-displaced Syrians. Media, War \& Conflict.

Moher, D., Liberati, A., Tetzlaff, J., Altman, D. G., \& Group, a. t. P. (2009). Preferred reporting items for systematic reviews and meta-analyses: The PRISMA statement. Annals of Internal Medicine, 151(4), 264-269.

Mooren, G. T. M., \& Kleber, R. J. (2001). The impact of war in Bosnia and Herzegovina: Devastated trust. International Journal of Mental Health, 30(2), 6-21.

Muecke, M. A. (1995). Trust, abuse of trust, and mistrust among Cambodian refugee women: A cultural interpretation. In E. V. Daniel \& J. Knudsen (Eds.), Mistrusting Refugees (Vol. 36). University of California Press.

Nickerson, A., Liddell, B. J., Keegan, D., Edwards, B., Felmingham, K. L., Forbes, D., \& Bryant, R. A. (2019). Longitudinal association between trust, psychological symptoms and community engagement in resettled refugees. Psychological Medicine, 49(10), 1661-1669.

Níraghallaigh, M. (2014). The causes of mistrust amongst asylum seekers and refugees: Insights from research with unaccompanied asylum-seeking minors living in the republic of Ireland. Journal of Refugee Studies, 27(1), 82-100.

Noyes, J., Booth, A., Moore, G., Flemming, K., Tunçalp, Ö., \& Shakibazadeh, E. (2019). Synthesising quantitative and qualitative evidence to inform guidelines on complex interventions: Clarifying the purposes, designs and outlining some methods. BMJ Global Health, 4(Suppl 1), e000893.

O’Donnell, C. A., Higgins, M., Chauhan, R., \& Mullen, K. (2008). Asylum seekers' expectations of and trust in general practice: A qualitative study. British Journal of General Practice, 58(557), 870-876.

Phinney, J. S., Madden, T., \& Santos, L. J. (1998). Psychological variables as predictors of perceived ethnic discrimination among minority and immigrant adolescents 1. Journal of Applied Social Psychology, 28(11), 937-953.

Rainbird, S. (2012). Distrust and collaboration: Exploring identity negotiation among asylum seekers in East Anglia, Britain. Journal of Intercultural Studies, 33(2), 139-156. 
Renzaho, A., \& Polonsky, M. J. (2013). The influence of acculturation, medical mistrust, and perceived discrimination on knowledge about blood donation and blood donation status. Transfusion, 53, 162S171S.

Renzaho, A., Polonsky, M., McQuilten, Z., \& Waters, N. (2013). Demographic and socio-cultural correlates of medical mistrust in two Australian States: Victoria and South Australia. Health and Place, 24, 216224.

Ryder, A. G., Alden, L. E., \& Paulhus, D. L. (2000). Is acculturation unidimensional or bidimensional? A head-to-head comparison in the prediction of personality, self-identity, and adjustment. Journal of Personality and Social Psychology, 79(1), 49.

Scheier, M. F., \& Carver, C. S. (1985). Optimism, coping, and health: assessment and implications of generalized outcome expectancies. Health Psychology, 4(3), 219.

Simandan, D. (2019). Revisiting positionality and the thesis of situated knowledge. Dialogues in Human Geography, 9(2), 129-149.

Tong, A., Flemming, K., McInnes, E., Oliver, S., \& Craig, J. (2012). Enhancing transparency in reporting the synthesis of qualitative research: ENTREQ. BMC Medical Research Methodology, 12(1), 181.

UNHCR (2021). What is resettlement? https://www.unhcr.org/resettlement.html

Vårheim, A. (2014a). Trust and the role of the public library in the integration of refugees: The case of a Northern Norwegian city. Journal of Librarianship and Information Science, 46(1), 62-69.

Vårheim, A. (2014b). Trust in libraries and trust in most people: Social capital creation in the public library. The Library Quarterly, 84(3), 258-277.

Verkuyten, M. (1998). Perceived discrimination and self-esteem among ethnic minority adolescents. The Journal of Social Psychology, 138(4), 479-493.

Withers, C. W. (2018). Trust-in geography. Progress in Human Geography, 42(4), 489-508.

Worchel, P. (1979). Trust and distrust. The social psychology of intergroup relations, 174, 187.

Publisher's Note Springer Nature remains neutral with regard to jurisdictional claims in published maps and institutional affiliations. 